\title{
Thermal investigation of light emitting diodes
}

\author{
K. Domke \& K. Wandachowicz \\ Poznan University of Technology, Poland
}

\begin{abstract}
High power light emitting diodes are already a popular alternative to incandescent and fluorescent lamps and it seems that in around a dozen years or so they may become the basic type of lamp used in lighting engineering. In addition to emitting light, LEDs also generate a significant quantity of heat. The assumption is that ca. $75 \%$ of total power is released in the form of heat which must be carried into the environment. Heat released in the p-n junction of the semiconductor material markedly increases its temperature and thus indirectly affects the photometric and electric characteristics of LEDs. The paper below presents a test stand designed for measuring such characteristics for a wide range of changes of junction temperatures. Junction temperature adjustment can proceed independently of the thermal power released in the LED. Selected measured characteristics of HP LEDs are also presented.
\end{abstract}

Keywords: light emitting diode, junction temperature, photometric measurement.

\section{Introduction}

Semiconductor LEDs made in the solid state lightning (SSL) technology can be divided into low power (LEDs) and high power (HP LEDs). The latter represent the most advanced group of light sources used in the lighting industry for general and decorative lighting applications and in the automotive industry for marker lights, stop lights, direction indicator lights and car headlights. The LED market is now a major and rapidly developing segment of the electronics market. Forecast growth of the LED technology (published in 2002) is presented in table 1 (supplemented by 2007 data).

In the LED markets White High Brightness LEDs will fuel growth to surpass $\$ 14$ billion by 2017. The present LED market by value is as in table 2:

The manufacturing technology of light emitting diodes has been growing exponentially in recent years. Different types and forms of LEDs have varied 
electric and photometric parameters. A thorough examination of LED properties is required to construct a luminaire system or vehicle lights with preset input parameters. A factor of basic significance is the relationship between electric/photometric parameters and the working temperature $T_{j}$ of the $p-n$ junction. Specification sheets for light emitting diodes provide electric parameters (forward voltage $U_{F}$ ) and photometric parameters (luminous flux $\Phi$, colour temperature $\mathrm{T}_{\mathrm{c}}$, chromaticity coordinates $\mathrm{xy}$ ) for a set value of the forward current $I_{F}$ in the p-n junction working temperature $T_{j}$ of $25^{\circ} \mathrm{C}$, whereas typical operating temperature $T_{j}$ of the $p-n$ junction in HP LEDs (with the power value of several watts) exceed $100^{\circ} \mathrm{C}$. As the temperature of the p-n junction rises, luminous flux $\Phi$ and forward voltage $U_{F}$ values drop, accompanied by a shift of the wavelength $\lambda_{\mathrm{m}}$ representing maximum spectral distribution to a higher wavelength. Luminaire manufacturers use a variety of means to reduce the temperature $\left(T_{j}\right)$ of the $p-n$ junction. LEDs are typically installed on heatsinks which, by substantially improving the process of transferring heat generated in the $\mathrm{p}-\mathrm{n}$ junction into the environment, reduce the temperature $\mathrm{T}_{\mathrm{j}}$ of the junction.

Table 1: $\quad$ Forecast growth of the SSL-LED technology according to a report prepared by OIDA (Optoelectronics Industry Development Association) [1-4].

\begin{tabular}{|l|c|c|c|c|c|c|c|}
\hline & Estimate & Data & \multicolumn{1}{c|}{ Estimate } & Data & Data \\
\hline & \multicolumn{5}{|c|}{ SSL-LED } & Incandesc. & Fluoresc. \\
\hline \multicolumn{1}{|c|}{ Parameter } & 2002 & 2007 & 2008 & 2012 & 2020 & 2007 & 2007 \\
\hline Luminous eff. [1m/W] & 25 & 75 & $45-100$ & 150 & 200 & 16 & 85 \\
\hline Life time [10 $3 \mathrm{~h}]$ & 20 & $>20$ & $35-50$ & $>100$ & $>100$ & 1 & 10 \\
\hline Lumin. flux [lm/lamp] & 25 & 200 & - & 1000 & 1500 & 1200 & 3400 \\
\hline Power [W/lamp] & 1 & 2.7 & - & 6.7 & 7.5 & 75 & 40 \\
\hline
\end{tabular}

Table 2: $\quad$ Industrial application LED market 2003-2008 (US\$ millions).

\begin{tabular}{|c|c|c|c|c|c|c|}
\hline \multicolumn{6}{|c|}{ Data } & Estimate \\
\hline 2003 & 2004 & 2005 & 2006 & 2007 & 2008 & 2017 \\
\hline 280 & 379 & 425 & 477 & 623 & 817 & 14000 \\
\hline
\end{tabular}

\section{LED structure}

LEDs are p-n junction devices constructed of gallium arsenide (GaAs), gallium arsenide phosphide (GaAsP), gallium phosphide (GaP) and especially HP LED: aluminium indium gallium phosphide (AlInGaP) or indium gallium nitride (InGaN). Silicon and germanium are not suitable because those junctions produce too much heat and no appreciable IR or visible light. The junction in an LED is forward biased and when electrons cross the junction from the $n$ - to the p-type material, the electron-hole recombination process produces some photons in the UV, IR or VIS in a process of electroluminescence. In non-radiative 
recombination events, the energy released during the electron-hole recombination is converted to phonons. Phonon is a quantised mode of vibration occurring in a rigid crystal lattice that increase temperature and produce heat. A typical design of low and high power light emitting diodes is shown in fig. 1.

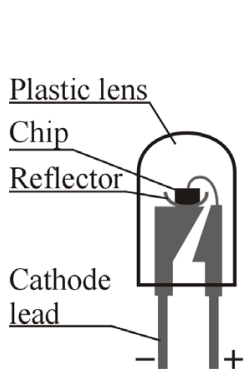

(a)

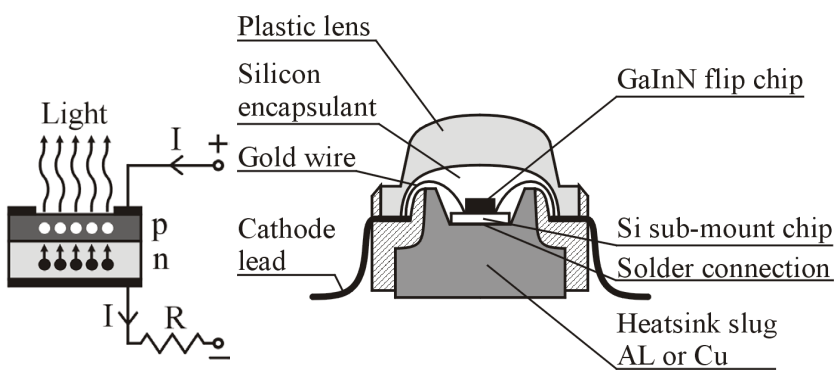

(b)

Figure 1: $\quad$ Structure of LED: (a) low power, (b) high power.

Low power diodes are usually made in the through-hole technology and operate without additional heatsink slugs. High power light emitting diodes (HP LEDs) made in the surface mount technology (SMT) have a different design. LEDs of this type, are designed in such a way as to allow easy take away heat from the p-n junction to the metal diode base, as illustrated in fig. 1(b).

HP LEDs are usually placed on a metallic core printed circuit board (MCPCB), often with an additional heatsink slug. Currently manufactured LEDs are generally installed on MCPCB sections and they are assembled in the finished product (e.g. in a luminaire) by mechanical fastening to the heatsink surface, as shown in fig. 2.

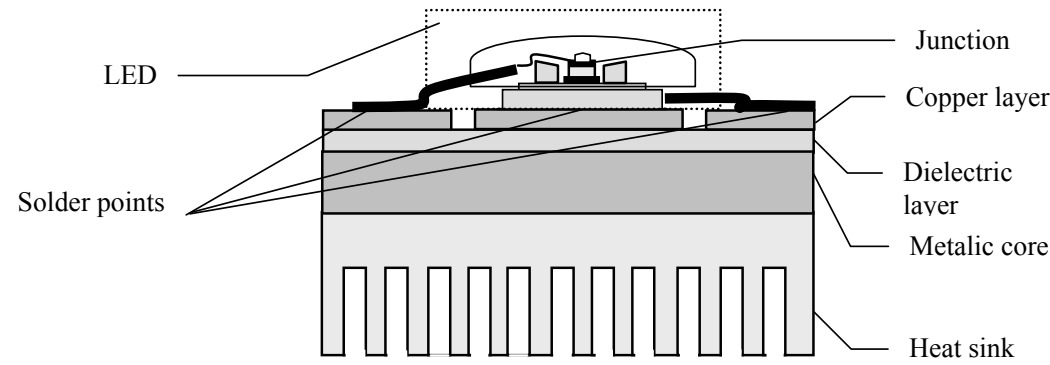

Figure 2: $\quad$ HP LED fastened on MCPCB with a heatsink slug.

\section{Heat flow in LEDs}

Processes taking place in HP LEDs generate a considerable amount of heat. Most of the heat is released in the $\mathrm{p}-\mathrm{n}$ junction during the flow of the current $\mathrm{I}_{\mathrm{F}}$. Joule heat generated in voltage conductors supplying voltage to the $p-n$ structure is practically negligible. A characteristic feature to note is the small area (volume 
of the p-n structure) which produces heat. This results in very high heat power densities and consequent difficulties with dissipating such large amounts of heat. The table 3 is illustrated lists of data for standard currently manufactured LEDs.

Table 3: $\quad$ Standard HP LED specifications $[5,6]$.

\begin{tabular}{|l|c|c|c|c|c|}
\hline LED type & $\begin{array}{c}\text { Total power } \\
\mathrm{P}=\mathrm{U}_{\mathrm{F}} \mathrm{I}_{\mathrm{F}}[\mathrm{W}]\end{array}$ & $\begin{array}{c}\text { Efficiency } \\
\eta[\%]\end{array}$ & $\begin{array}{c}\text { Heat power } \\
\mathrm{P}_{\mathrm{th}}=(1-\eta) \mathrm{P}[\mathrm{W}]\end{array}$ & $\begin{array}{c}\text { Max junc. } \\
\text { temp. } \mathrm{T}_{\mathrm{j}}\left[{ }^{\circ} \mathrm{C}\right]\end{array}$ & $\begin{array}{c}\text { Heat power dens } \\
\mathrm{q}=\mathrm{P}_{\mathrm{th}} / \mathrm{S}\left[\mathrm{W} / \mathrm{m}^{2}\right]\end{array}$ \\
\hline $\begin{array}{l}\text { C460XB90 } \\
\text { 0-S92xx-A }\end{array}$ & 1.2 & 14 & 0.98 & 125 & $1.4 \cdot 10^{6}$ \\
\hline EZ1000 & 3.8 & 28 & 2.7 & 145 & $3.1 \cdot 10^{6}$ \\
\hline $\begin{array}{l}\text { OSTAR } \\
\text { LEWE3A }\end{array}$ & 27 & 28 & 19.4 & 150 & $2.9 \cdot 10^{6}$ \\
\hline
\end{tabular}

Heat generated in the junction must be carried into the environment. Initially, some heat is dissipated as a result of thermal conduction via internal LED components from the p-n structure area to the external LED components (e.g. to the MCPCB base). A description of the phenomenon is based on the notion of the so-called thermal resistance $\mathrm{R}_{\mathrm{th}}$. Thermal resistance Hewitt et al. [7] and Wong [8] define as:

$$
R_{t h, x-y}=\frac{T_{x}-T_{y}}{P_{t h}}
$$

where $\mathrm{T}_{\mathrm{x}}$ and $\mathrm{T}_{\mathrm{y}}$ stand for $x$ or $y$ surface temperatures and $\mathrm{P}_{\text {th }}$ denotes thermal power flowing between those surfaces.

The appropriate formula for calculating thermal resistance $\mathrm{R}_{\mathrm{th}}$ can be found in literature on thermal conduction in solids [7,8].

In HP LEDs (cf. fig. 1(b)) the direction of the main heat flux is from the p-n junction to the metal heatsink slug and to metal anode and cathode leads soldered to the PCB. The heat flux through non-metallic elements of the diode to the external epoxy housing and the lens accounts for no more than $1 \%$ of $\mathrm{P}_{\text {th }}$ and can be disregarded. Resistances $R_{\text {th }}$ which occur in the internal heat flow path are referred to as internal thermal resistances. A connection diagram for thermal resistances inside a LED is shown in fig. 3.

LED internal thermal resistances are difficult to measure and are strictly related to the internal design of specific LED types. Diode manufacturers are striving to work out designs with reduced thermal resistance levels. Reductions in $\mathrm{R}_{\mathrm{th}, \mathrm{j}-\mathrm{sp}}$ levels resulting from modifications in LED design are shown in fig. 4.

Manufacturers generally specify only the total thermal resistance $R_{t h, j-s p}$ measured between the semiconductor junction inside the diode and its metallic core $[5,6]$. In order to ensure adequate cooling of HP LEDs, the base of the diode is soldered or fastened (e.g. screwed down) to a suitable external heatsink with thermal resistance $\mathrm{R}_{\mathrm{th}}$, heatsink.

Thermal power $\mathrm{P}_{\text {th }}$ is carried from the heatsink surface: by convection to the gas surrounding the heatsink (with temperature $T_{\text {amb,conv }}$ ) and by radiation to 

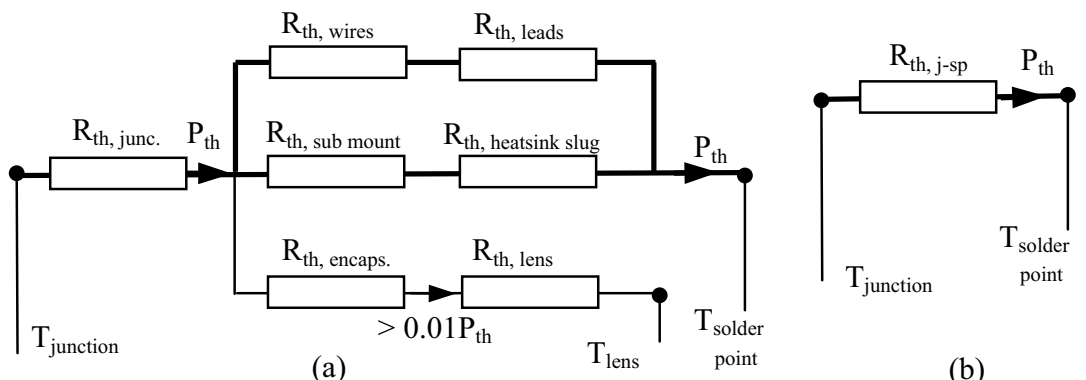

(a)

(b)

Figure 3: Diagram for internal thermal resistances of LEDs: (a) full, (b) simplified. Main heat flow paths are marked with bold lines. Denotes as in figs. 1-2.

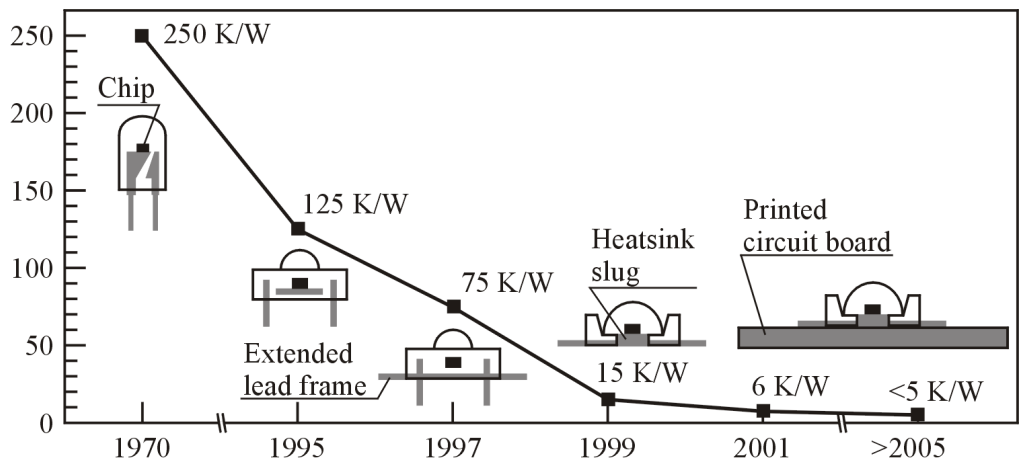

Figure 4: Thermal resistance of LED packages (adopted from Arik et al., 2002).

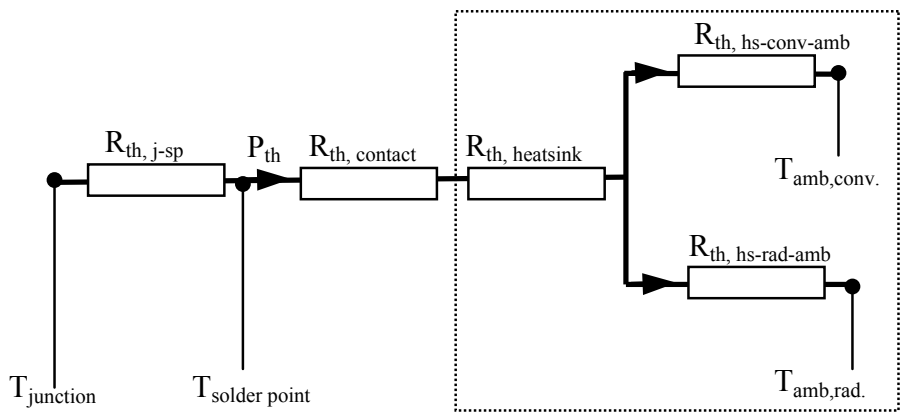

Figure 5: Diagram for thermal resistances of a LED installed on the heatsink. 
other bodies surrounding the heatsink (with temperature $\mathrm{T}_{\mathrm{amb}, \text { rad. }}$ ). Corresponding thermal resistances are marked as $\left(\mathrm{R}_{\text {th, hs-conv-amb }}\right)$ and $\left(\mathrm{R}_{\text {th, hs-rad-amb }}\right)$. In specific cases, temperatures $T_{a m b, c o n v}$ and $T_{a m b, r a d}$ can differ. Heatsink manufacturers usually specify total thermal resistance $\mathrm{R}_{\text {th, heatsink-amb. and recommend assuming }}$ that $\mathrm{T}_{\mathrm{amb}}=0.5\left(\mathrm{~T}_{\mathrm{amb}, \mathrm{conv}}+\mathrm{T}_{\mathrm{amb}, \mathrm{rad}}\right)$.

The external heatsink is intended to dissipate the thermal power $\mathrm{P}_{\mathrm{th}}$ from the diode into the environment. It can be calculated using the formula below:

$$
P_{t h}=(1-\eta) P=\frac{T_{j}-T_{a m b}}{R_{t h, t o t}}
$$

where $\mathrm{P}=\mathrm{U}_{\mathrm{F}} \cdot \mathrm{I}_{\mathrm{F}}$ stands for the power of electric losses on the diode, $\eta$ denotes its efficiency and $\mathrm{R}_{\mathrm{th} \text {,tot }}$ stands for total thermal resistance between the $\mathrm{p}-\mathrm{n}$ junction and the environment with the temperature $\mathrm{T}_{\mathrm{amb}}$ :

$$
R_{t h, t o t}=R_{t h, j-s p}+R_{t h, \text { contact }}+R_{\text {th, heatsink-amb }}
$$

where $\mathrm{R}_{\text {th,heatsink-amb }}$ denotes total thermal resistance of the heatsink and $\mathrm{R}_{\mathrm{th} \text {,contact }}-$ thermal resistance of the diode - heatsink connection. The specifications are provided by manufacturers and are the basic factors determining heatsink choice. The formulas given in (2) and (3) show that heatsinks should be selected in such a way as to make the total thermal resistance satisfy the following relationship:

$$
R_{t h, \text { heatsink-amb }}+R_{\text {th, contact }}<\frac{T_{j}-T_{a m b}}{P_{t h}}-R_{t h, j-s p}=\frac{T_{s p}-T_{a m b}}{P_{t h}}
$$

\section{Temperature-dependent photometric and electric characteristics. Methods for determining junction temperature}

Junction temperature $T_{j}$ is an important parameter which has a major effect on failure-free LED operation, as well as a range of photometric and electric characteristics. If the permitted temperature level is exceeded, the semiconductor unit is permanently damaged. $T_{j}$ increasing above $T_{a m b}$ causes a deterioration of LED operating characteristics, as illustrated in fig. 6.
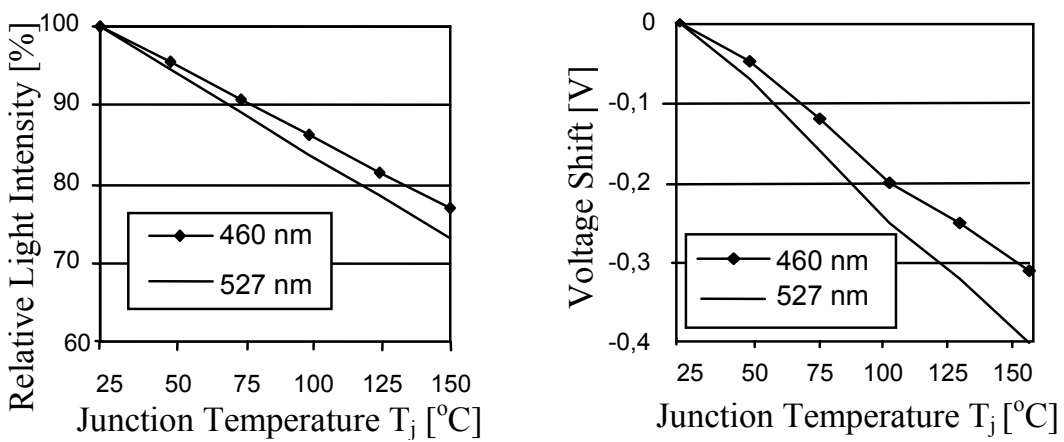

Figure 6: $\quad$ Specifications of EZ1000 LED for $\mathrm{I}_{\mathrm{F}}=350 \mathrm{~mA}$. [4] 
Unfortunately, junction temperature $\left(T_{j}\right)$ is not a directly measurable quantity. The most frequently used means of determining junction temperature is an indirect method based on determining e.g. the standard relation between the LED forward voltage and junction temperature $U_{F}=f\left(T_{j}\right)$ in the course of special test measurements. Measurements are carried out after placing the entire LED structure in the heat chamber maintaining constant temperature, adjusting the temperature of the entire semiconductor unit at a uniform level. A momentary current pulse is then applied to the LED. The pulse must be so short as not to produce any thermal effects and, at the same time, make it possible to measure electric quantities. The characteristic $\mathrm{U}_{\mathrm{F}}=\mathrm{f}\left(\mathrm{T}_{\mathrm{j}}\right)$ thus obtained is then used to determine junction temperature $T_{j}$ during measurements of photometric quantities performed as the LED is supplied with direct current in conditions similar to normal LED operations.

The main shortcoming of the method outlined above is the assumption that the $U_{F}=f\left(T_{j}\right)$ characteristic determined in testing conditions also reflects the relationship in operating conditions, although LED temperature distribution is completely different in both cases.

\section{Test stand for performing thermal measurements of LEDs}

The basic aim of constructing the test stand was to create appropriate conditions for performing LED tests focused on electric and photometric characteristics in the function of the variable temperature $\mathrm{T} j$ of the $\mathrm{p}-\mathrm{n}$ junction, with a constant, freely set value of forward current intensity $\mathrm{I}_{\mathrm{F}}$. In order to achieve the objective, it was necessary to come up with a system which, in addition to standard measurements of electric and photometric parameters, would also ensure adjustable inflow or outflow of thermal power $\mathrm{P}_{\text {th }}$ to the $\mathrm{p}-\mathrm{n}$ junction.

LEDs selected for testing (fig. 2) are mounted on a metallic MCPCB base with high thermal conductivity $\lambda$. The base is fastened to the metal block $(\mathrm{Cu})$, with a Peltier element placed on the opposite surface (see fig. 7).

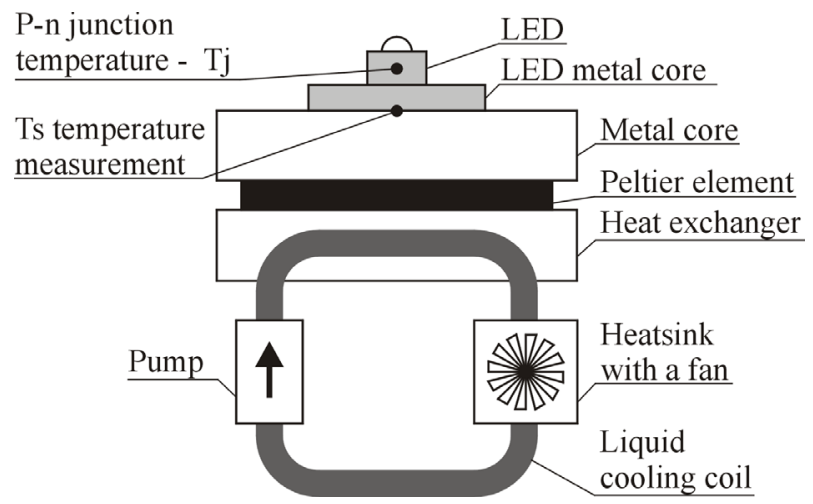

Figure 7: Diagram illustrating the test stand designed for performing tests of thermal characteristics of light emitting diodes (LEDs). 
When voltage is applied the Peltier element, the current $\mathrm{I}_{\mathrm{Plt}}$ is generated, producing a temperature difference which is conducive to the flow of thermal power $\mathrm{P}_{\text {th }}$ from the LED to the heat exchanger. Therefore, the Peltier element acts as a pump with adjustable delivery rate, transferring thermal power from the LED to the heat exchanger. A connection diagram of thermal resistances of the test stand is presented below:
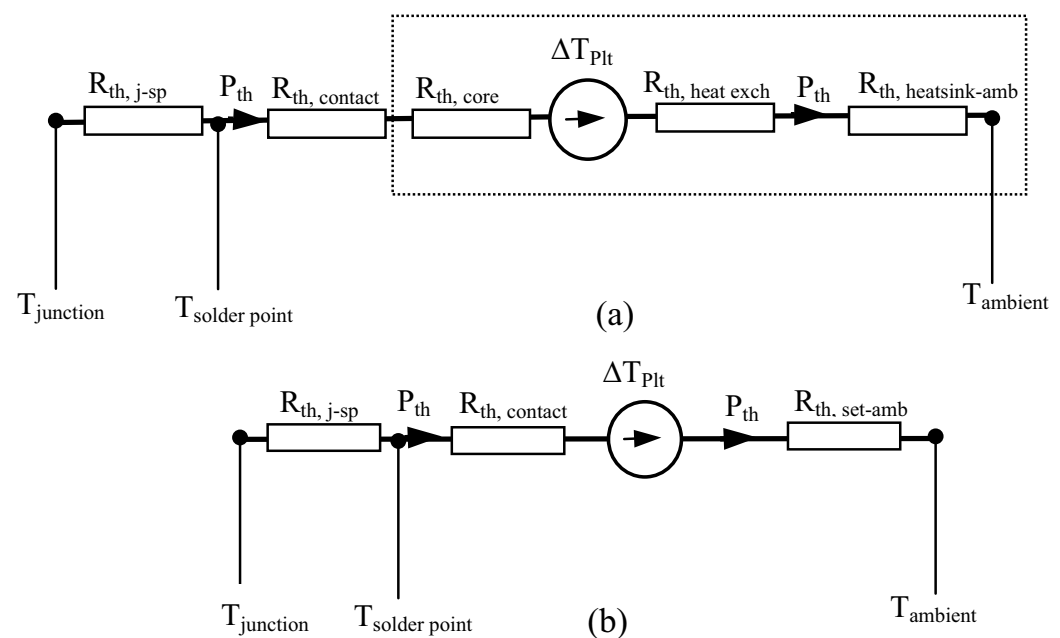

Figure 8: Diagram for thermal resistances of the test stand: (a) full, (b) simplified.

In fig. 8, the Peltier element is shown as a source of temperature difference $\Delta \mathrm{T}_{\text {Plt }}$ (equivalent to the source of voltage) produced by the flow of current with the current intensity $\mathrm{I}_{\mathrm{Plt}}$. $\Delta \mathrm{T}_{\mathrm{Plt}}$ can be adjusted by changes in the current intensity $\mathrm{I}_{\mathrm{Plt}}$, while the sign of the temperature difference - its direction. Consequently, by changing the polarity of voltage applied to the Peltier element, you may obtain an effect of $p-n$ junction cooling or heating.

Analysing the thermal circuit given in fig. 8, you derive the following:

$$
P_{t h}=\frac{T_{j}-T_{P l t 1}}{R_{t h, j-s p}+R_{\text {th,contact }}}=\frac{T_{P l t 2}-T_{a m b}}{R_{t h, \text { set-amb }}}
$$

and determining the temperature difference produced on the Peltier element as $\Delta T_{P l t}=T_{P l t 1}-T_{P l t 2}$, the relationship (6) is derived describing the thermal relations found in the analysed test stand.

$$
T_{j}=P_{t h}\left(R_{t h, j-s p}+R_{t h, \text { contact }}+R_{t h, s e t-a m b}\right)-\Delta T_{P l t}+T_{a m b}
$$

Analysing the formula in (6), it follows that it is possible to obtain a preset junction temperature at any power $\mathrm{P}_{\text {th }}$ by selecting an appropriate value of $\Delta \mathrm{T}_{\mathrm{Plt}}=\mathrm{f}\left(\mathrm{I}_{\mathrm{Plt}}\right)$. The temperature is obtained without interfering with the power $\mathrm{P}_{\text {th }}$ 
generated in the diode. Given the sufficient efficiency of the Peltier element, it is possible to achieve junction temperatures that are lower than the ambient temperature. The test stand described here thus makes it possible to obtain preset junction temperatures for a broad range of changes of thermal power generated in the LED. $\mathrm{P}_{\text {th }}$ and $\mathrm{T}_{\mathrm{j}}$ can be adjusted independently.

The temperature of the junction $\mathrm{T}_{\mathrm{j}}$ was determined indirectly, using the formula :

$$
T_{j}=R_{t h j-s p} P_{t h}+T_{s p}
$$

where temperature $T_{\mathrm{sp}}$ was measured in the central point at the contact surface of the LED's MCPCB with the metal base of the test stand (cf. fig. 7). Measurements were performed using a K thermocouple $(\varnothing 0.2 \mathrm{~mm})$ in the steady thermal state. The value of thermal resistance $R_{\text {thj-sp }}$ was assumed according to the manufacturer's specifications. Thermal power was defined on the basis of measurements of LED electric parameters. The use of the formula given in (7) to determine the junction temperature $\mathrm{T} j$ is recommended by manufacturers of light emitting diodes. As a consequence, it is assumed that thermal resistance $R_{\text {thj-sp }}$ was determined for total power supplied to the diode $\left(\mathrm{P}_{\mathrm{th}}=\mathrm{U}_{\mathrm{F}} * \mathrm{I}_{\mathrm{F}}\right)$.

\section{Thermal photometric characteristics}

Measurements were carried out for two types of light emitting diodes [2, 3] (table 4). The test stand made it possible to obtain a wide range of temperatures to measure temperature characteristics of the examined diodes.

Table 4: Catalogue specifications of light emitting diodes: maximum permitted levels are given in brackets $[5,6]$.

\begin{tabular}{|c|c|c|c|c|c|c|}
\hline No & LED type & $\mathrm{I}_{\mathrm{F}}[\mathrm{mA}]$ & $\mathrm{U}_{\mathrm{F}}[\mathrm{V}]$ & $\Phi[\mathrm{lm}]$ & $\mathrm{T}_{\mathrm{j}}\left[{ }^{0} \mathrm{C}\right]$ & $\mathrm{R}_{\text {thj-sp }}[\mathrm{K} / \mathrm{W}]$ \\
\hline 1 & $\begin{array}{c}\text { K2 Star } \\
\text { L2K2-MWW4 }\end{array}$ & $\begin{array}{c}1000 \\
(1500)\end{array}$ & 3,72 & 100 & $\begin{array}{c}110 \\
(150)\end{array}$ & 13 \\
\hline 2 & $\begin{array}{c}\text { Ostar } \\
\text { LE W E3A }\end{array}$ & $\begin{array}{c}700 \\
(1000)\end{array}$ & 20,8 & $240 \div 520$ & $\begin{array}{c}150 \\
(180)\end{array}$ & 3 \\
\hline
\end{tabular}

Investigation in the proposed measurement system give the lowest $\left(-9.1^{\circ} \mathrm{C}-\right.$ $\mathrm{K} 2 \mathrm{Star}, 1.2^{\circ} \mathrm{C}-$ Ostar) and the highest temperatures of the solder point $\mathrm{T}_{\mathrm{s}}$ $\left(119^{\circ} \mathrm{C}-\mathrm{K} 2\right.$ Star, $135.1^{\circ} \mathrm{C}-$ Ostar) and the $\mathrm{p}$-n junction temperature $\mathrm{T}_{\mathrm{j}}$ $\left(45.5 \div 167.8^{\circ} \mathrm{C}-\mathrm{K} 2\right.$ Star, $42.3 \div 174.1^{\circ} \mathrm{C}-$ Ostar).

Sample results showing changes of the luminous flux $\Phi$ and the forward voltage $U_{F}$ in the function of junction temperature are given in fig. 9. The characteristics corroborate the relationship between the luminous flux and the temperature of the junction. For recommended maximum operating temperatures of the p-n junction $\left(110^{\circ} \mathrm{C}\right.$ and $150^{\circ} \mathrm{C}$ cf. table 5), flux reduction - in relation to catalogue specifications - is considerable, amounting to $26 \%$ (K2 Star) and $32 \%$ (Ostar). 


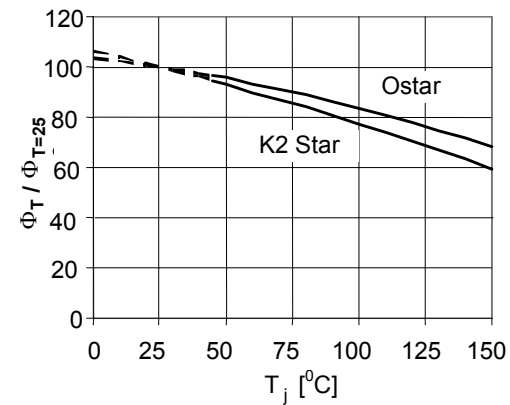

(a)

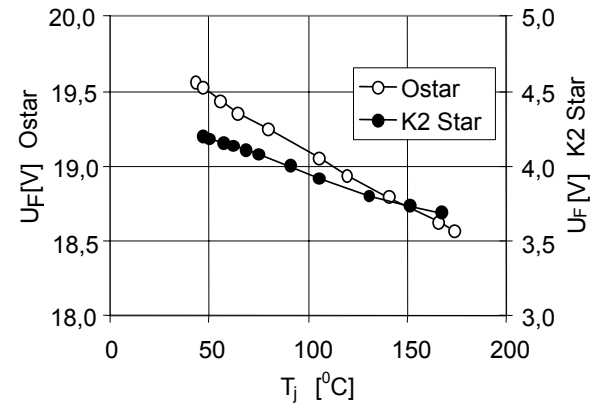

(b)

Figure 9: $\quad$ For constant forward current $\mathrm{I}_{\mathrm{F}}$ : $1000 \mathrm{~mA}(\mathrm{~K} 2 \mathrm{Star})$ and $700 \mathrm{~mA}$ (Ostar): (a) Relative changes of the thermal flux and (b) Changes of the forward voltage $U_{F}$ in the function of the junction temperature $\mathrm{T}_{\mathrm{j}}$.

The extrapolation of measurement curves for low temperature (broken lines in fig. 9) resulted from the impossibility to achieve the assumed temperature of the $\mathrm{p}-\mathrm{n}$ junction, despite obtaining negative temperature at the solder point $\mathrm{T}_{\mathrm{sp}}$. The Peltier element was not adequately efficient and the value of the temperature difference $\Delta \mathrm{T}_{\mathrm{Plt}}$ proved insufficient. The defect will be eliminated in the subsequent version of the test stand.

Figure 9 presents the temperature characteristics of changes in the forward voltage $U_{F}$ of selected diodes. Within the range of $p-n$ junction temperature changes between $50^{\circ} \mathrm{C}$ and $150^{\circ} \mathrm{C}$, the mean coefficient of forward voltage change was $4.4 \mathrm{mV} /{ }^{\circ} \mathrm{C}(\mathrm{K} 2 \mathrm{Star})$ and $7.4 \mathrm{mV} /{ }^{\circ} \mathrm{C}$ (Ostar). In view of the typical voltage-current characteristic of LEDs, where minor changes of the forward voltage $U_{F}$ produce major changes of the forward current intensity $I_{F}$, diode supply should be provided in the form of systems of stabilised current supplies, not voltage supplies.

\section{References}

[1] Optoelectronic Component Industry to 2008. Reed Electronics Research. http://www.rer.co.uk.

[2] http://www.netl.doe.gov/ssl/PDFs/lifetimeWhiteLEDs_aug16_r1.pdf

[3] Klipstein, D. L. The Brightest and Most Efficient LEDs and where to get them. Don Klipstein's Web Site: http://members.misty.com/don/ledx.html

[4] Light Emitting Diodes for General Illumination. An OIDA Technology Roadmap. October 2002.

[5] Cree EZ 000 LEDs. http://www.cree.com/products/pdf/CPR3CR.pdf

[6] Ostar Lightning. Application note. www.osram-os.com

[7] Hewitt G. F., Shires G. L., Bott T.R., Process Heat Transfer, CRC Press, Boca Raton, N. York, 1994.

[8] Wong K-F. V. Intermediate Heat Transfer. Marcel Dekker Inc. N. York, 2003. 